\title{
Acetylcholinesterase-positive nerves of the rhesus monkey bronchial tree
}

\author{
A L - W A L I D I. E L-BER M A N I \\ a n d MAR G ARET GR A T
}

Department of Anatomy, Boston University School of Medicine, Boston, Massachusetts, USA

\begin{abstract}
El-Bermani, A-W. I. and Grant, Margaret (1975). Thorax, 30, 162-170. Acetylcholinesterase-positive nerves of the rhesus monkey bronchial tree. The rhesus monkey lung was stained both by histological methods and histochemically for specific acetylcholinesterase (AChE). AChE-containing nerves in bundles were demonstrated in connective tissue of the hilum and in association with clusters of ganglion cells. These bundles become associated with the bronchial tree as they enter the lung parenchyma, and their numbers of myelinated fibres diminish as they pass scattered ganglion cells along the bronchial system. Extrachondral and subchondral plexuses of nerves were found to be interconnected and to contribute to the perimuscular varicose nerve plexus of the bronchi and bronchioles. These nerve plexuses were found to extend as far as the respiratory bronchioles.

In the bronchial submucosa there are AChE-positive nerve plexuses which arise from three sources: (1) the adventitial plexus in bronchioles, or the subchondral plexus in bronchi, (2) the perimuscular nerve plexus, and (3) AChe-containing nerves associated with the bronchial artery. The submucosal plexus appears to innervate the acinar submucosal glands in bronchi as well as continuing as central nerves in the mucosal folds. In the bronchioles the nerves in the mucosal fold are in close relationship with the mucosa.
\end{abstract}

The pulmonary innervation is derived mainly from the autonomic nervous system (Kuntz, 1953; von Hayek, 1960). Pulmonary nerves arise from large plexuses found at the arch of the aorta and about the bifurcation of the trachea (Mitchell, 1956) and were classified by Larsell $(1921 ; 1922)$ as bronchial or vascular nerves.

Most previous anatomical studies have concentrated on rat, cat, and dog lungs (Larsell, 1921; Elftman, 1943; Honjin, 1956a and b; El-Bermani, McNary, and Bradley, 1970) with little attention to the innervation of the primate lung. Until recently much confusion has arisen from the idea that one mammalian species is very much like any other in terms of its pulmonary innervation. In addition, conflicting reports have arisen because of the staining artifacts of various histological techniques for neural tissue (Stirling, 1876; Larsell, 1921; Honjin, 1956a and b; Hirsch et al., 1968).

The present studies were undertaken to demonstrate the pattern and distribution of the bronchial innervation in an erect primate. Histological stain ing methods and a method specific for acetylio cholinesterase were used. The results indicate that acetylcholinesterase-containing nerves invest both muscular and glandular cells of submucosa glands in the bronchi and the mucosa of bronchioles. They further show that any classifica? tion of pulmonary nerves as 'vascular' of 'bronchial' is an artificial one since a significane. proportion of the bronchial innervation arises from that of the bronchial artery. Finally, then demonstrate marked differences between this primate and other 'lower' mammalian species those used more frequently for physiologicat study.

\section{METHODS}

Twelve adult Macaca rhesus monkeys were used for these studies. Lungs were judged to be non $\frac{\mathrm{D}}{\mathrm{D}}$ diseased at the time of necropsy. The lungs were dissected and one cubic inch blocks of tissue 
representing the hilum, the 'body', and the peripheral (subpleural) areas were selected randomly for histological and histochemical processing. A total of at least 24 such blocks for each animal was processed and examined. Histological staining by supravital methylene blue and two methods for silver impregnation were used to visualize the general distribution of nerves. Alternate sections were processed for histochemical study of acetylcholinesterase. The following methods were used for histological and histochemical staining:

1. Methylene Blue Staining According to the method described by Hillarp (1946) with modifications by El-Bermani et al. (1970), anaesthetized animals were injected intratracheally with sufficient amounts of $0.04 \%$ methylene blue in physiological saline containing glucose and magnesium bromide. The solution remained in the lungs for 12-15 minutes and was then withdrawn and the animal was placed on an artificial respirator for 30 minutes. The lungs were then removed and fixed in $8 \%$ ammonium molybdate containing 3 drops of $2 \%$ osmium tetraoxide per $100 \mathrm{ml}$ for 24 hours at $4^{\circ} \mathrm{C} ; 20 \mu$ frozen sections were placed on slides, air dried, and mounted with permount.

2. SILVER IMPREGNATION Silver impregnation was performed by two techniques. Paraffin sections of Bouin's fixed inflated lung were stained by the method of Fitzgerald (1964), while frozen sections of formol-cadmium chloride fixed lungs were impregnated by the method of Namba et al. (1967).

3. ACETYLCHOLINESTERASE (AChE) $25 \mu$ frozen sections were fixed in cold $\left(4^{\circ} \mathrm{C}\right)$ formol-saline and stained by a modification of Karnovsky and Roots' (1964) technique, as described by El-Badawi and Schenk (1966). Tetra isopropyl phosphoramide (iso OMPA) in a final concentration of $8 \times 10^{-8} \mathrm{M}$ was used to inhibit non-specific cholinesterase. Adjacent sections were simultaneously incubated in butrylthiocholine as a substrate for cholinesterase, and acetylthiocholine iodine was used as substrate for specific acetylcholinesterase.

Histological staining by both silver impregnation and supravital methylene blue has an advantage over silver impregnation alone, firstly because of the higher specificity of methylene blue for neural tissue, as demonstrated by neurochemical methods (acetylcholinesterase, nor- epinephrine), and secondly because of the higher resolving power of methylene blue. Most silver methods leave large silver grains which mask the outline of nerve cells and fibres as well as tending to stain connective tissue.

The Namba, Nakamura, and Grob (1967) technique of all the silver methods appears to be the most selective as it gives fairly high resolution of nervous structures. Combination methylene blue and silver staining with the histochemical method for specific acetylcholinesterase gives one a good picture of the general pattern of innervation and an indication of which proportion of that innervation contains significant amounts of acetylcholinesterase.

\section{RESULTS}

Bundles of large numbers of nerve fibres were demonstrated entering the hilum of the lung in connective tissue between blood vessels and bronchi with no association with any particular structure. After entering approximately one-third of the depth of the hilum the bundles become intimately associated with the adventitia of the bronchial system (Fig. 1). In large bronchi these bundles run outside the cartilagenous rings and in the trigonal area between the blood vessels and bronchi. These bundles are in closer relation to the cartilages than the centre of trigonal connective tissue. At the bronchiolar level the bundles are concentrated at the periphery of the adventitia. Both types of bundles are of mixed fibre populations with thick and thin fibres present (Fig. 1).

The number of thick nerve fibres differs from one bundle to the other. As sections proceed deep into the lung parenchyma a reduction in the number of thick fibres in each bundle becomes evident. The greater reduction is encountered when the nerve bundles contact ganglion cells along their course.

The ganglion cells are round or ovoid with an eccentric nucleus and granular cytoplasm, especially near the origins of axons. At the hilum (Fig. 2) the ganglion cells are grouped in large clusters in connective tissue. Both at the hilum and in the parenchyma of the lung most of the ganglion cells are concentrated at the bifurcations of the airways. In the bronchi, they are external to the cartilagenous plates.

The bronchiolar nerve bundles contribute nerve fibres to the musculature of the bronchiolar wall (Fig. 3). The fibres reaching the muscular coat of a bronchiole have a closer relation to the 


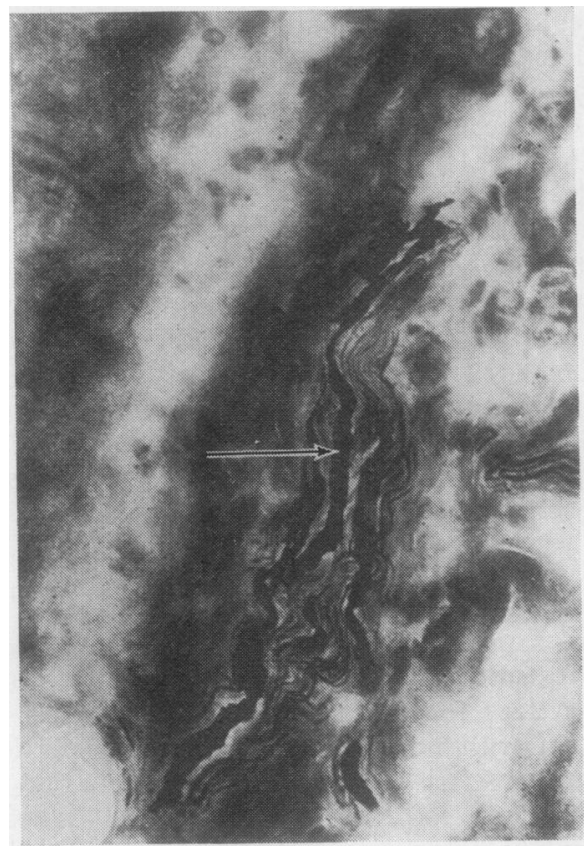

FIG. 1. A branching bundle of nerve fibres entering the lung near the hilum and containing a mixed population of myelinated (arrow) and non-myelinated nerve fibres (Silver impregnation $\times 260$ ).

muscle cells. These nerves form an intricate, intermeshed plexus of beaded fibres (Fig. 3). They are of the thin non-myelinated type and surround the surface of the bronchiolar muscle bands. The plexuses can be seen in any orientation of sectioning through the muscular coat of the bronchioles but are orientated about the circumference of the muscular bands generally, with interconnections along the radii of the bronchioles (Fig. 4). The complexity and density of these plexuses increase at the bifurcations of the bronchiolar system where they receive additional direct contributions from the scattered ganglion cells.

A number of nerve fibres have been identified in the submucosal and mucosal area. Most of these fibres originate in the muscular nerve plexus while some come directly from the adventitial plexus in the bronchiolar wall (Fig. 5). Both sources lead to a heavy innervation in the submucosal area. A few fibres were observed to proceed toward the lumen in the connective tissue of the mucosal fold. Some fibres were also found to reach the basal layer of mucosal cells and extended between the mucosal cells. They are a continuation of the innermost component of the submucosal nerves (Fig. 6).

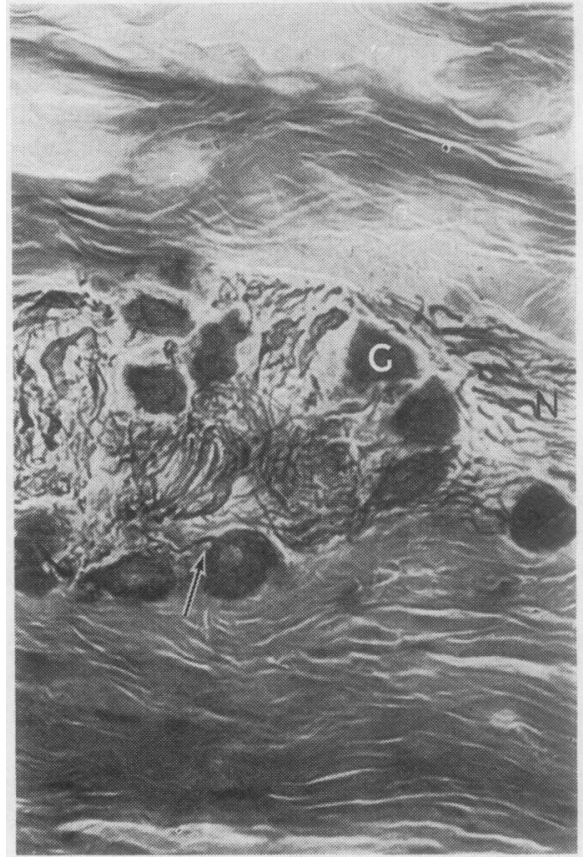

FIG. 2. A group of ganglion cells $(G)$ associated wit a nerve bundle $(N)$ near the hilum. Note the dens@ nerve fibres which cluster about the ganglion cell and occasionally can be seen to form endings on the cell (preganglionic nerves). A postganglionic axon ca $\vec{A}$ be seen to emerge from one of the cells (arrou (Silver impregnation $\times 260$ ).

AChE was identified in bundles of nerve fibres in the hilar area and in those fibres associate with the bronchial system. The latter were locate in the connective tissue external and internal to the cartilagenous plates (Fig. 7). In bronchioles where cartilagenous tissue is absent, the nerves bundles are based in adventitia. All the above? mentioned nerve bundles were composed of thic myelinated and thin non-myelinated fibres. The adventitial nerves will be called so at th bronchiolar level, but at the bronchial level wheres they divide on either side of the cartilagenous plates they will be termed extrachondral ang subchondral nerve plexuses.

The nerve plexuses of the muscular coat in the bronchial system were found to contain AChE These AChE-containing nerves form the characiteristic network of irregularly outlined nervE fibres seen with the histological methods (Fig. 8) They surround the smooth muscle bundles in ever plane of section and criss-cross each other. The density of the AChE-positive nerve plexuses is 


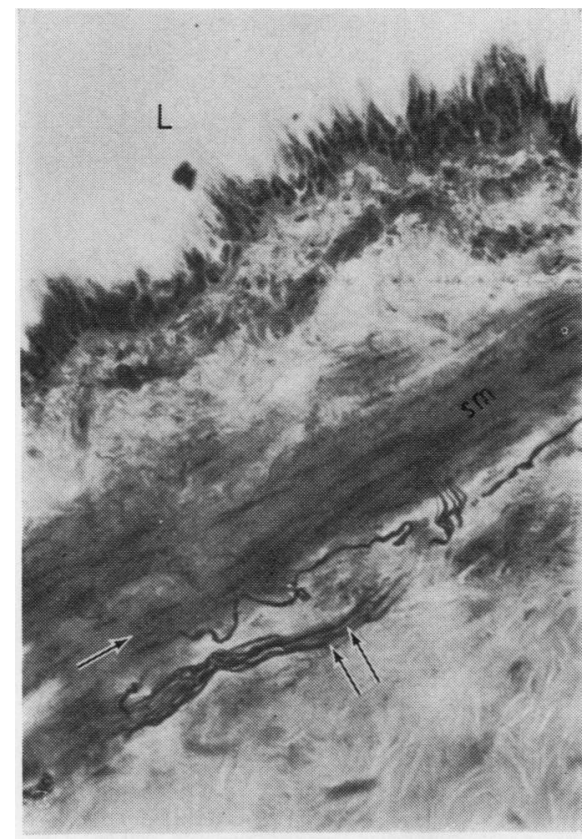

FIG. 3. Peribronchiolar nerve bundles which contribute innervation to the smooth muscle (sm) of the bronchiolar wall (double arrow). In the muscle the nerves form a varicose plexus (single arrow) ( $L=$ lumen) (Silver impregation $\times 126)$.

higher at the bifurcation points of the bronchiolar system.

In the submucosa of bronchioles, a large number of AChE-positive nerve fibres were identified. These submucosal fibres arise from both the AChE-positive perimuscular nerve plexus and as direct continuations of AChE-containing subchondral or adventitial nerve bundles. These submucosal fibres can be followed in the direction of the mucosa or circumferentially in submucosal tissue. In large bronchi where glands are present, the acinar cells are surrounded by AChE-containing nerve fibres (Fig. 7). The nerves of the muscular coat as well as those of the submucosa were present as far as the respiratory bronchioles.

Some of the bronchial arteries demonstrated AChE-positive nerves while other bronchial arteries had nerves negative for AChE. The AChE-containing nerves from bronchial arteries were observed to interconnect with perimuscular and submucosal nerve plexus of the bronchi (Fig. 7). This arrangement is prominent mainly in the hilar area, and no ganglion cells have been identified in association with bronchial artery.

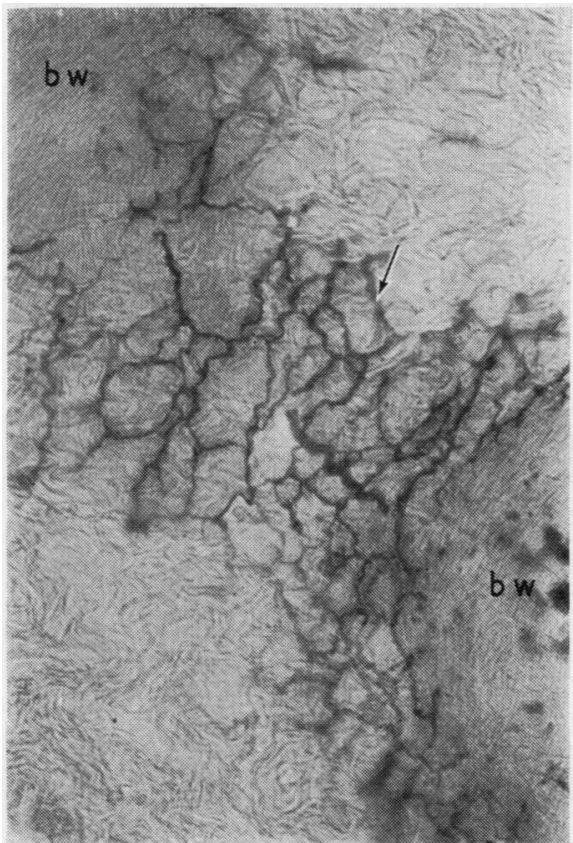

FIG. 4. Tangential section of a bronchiolar wall (bw) at a bifurcation point. A varicose nerve (arrow) plexus can be seen in the smooth muscle (Methylene blue $\times 126)$.

The ganglion cell clusters associated with the bundles of nerves (at the hilar area) are AChEpositive. Both thick and thin fibres were observed near and between the ganglion cells. A close inspection of these ganglion cells revealed fine plexuses of AChE-positive fibres dispersed over the surface of each ganglion. The plexuses can be seen to arise from large myelinated nerves (Fig. 9). In the periphery of the lung parenchyma the ganglion cells are scattered along the peribronchiolar nerve bundle and contribute AChEpositive nerves to the muscular nerve plexus and submucosal plexus.

\section{DISCUSSION}

Little work has been done on the anatomy of the innervation of primate lung despite the fact that the physiology of the erect primates approximates human physiology more closely than does that of lower species. The present results show marked differences between the innervation of the Rhesus monkey lung and that of other mammalian nonprimate species.

The major features of the innervation of the Rhesus bronchial system which differ from those 


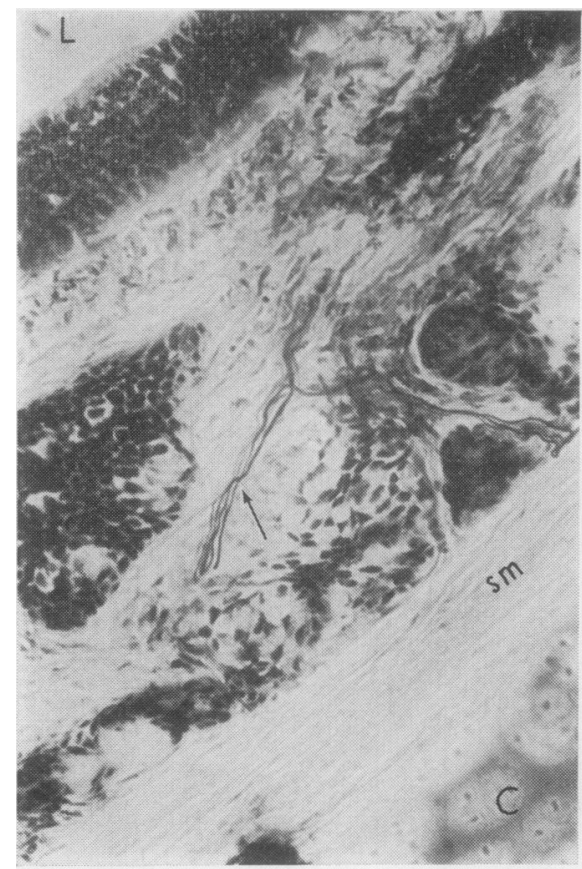

FIG. 5. Submucosal nerves. A group of thin nerve fibres (arrow) traverses the submucosal area in a bronchial wall. A cartilagenous plate is labelled $C$ (sm=smooth muscle; L=lumen) (Silver impregnation $\times 126)$.

of the other mammals involve the distribution of nerve types in the bronchial arteries, a pronounced AChE-containing innervation to acinar glands, and the pattern by which nerves enter the lung at the hilum.

At the hilar area in the rhesus monkey lung, there are large nerve bundles which have no definite association with any specific structure. This is in contrast to our findings in the rat lung (El-Bermani et al., 1970; El-Bermani, 1973a and b) and to the findings of others (Stirling, 1876; Dogiel, 1898; Hirsch et al., 1968) in other nonprimate species, that all entering structures, blood vessels, and airways had associated pulmonary nerves. In the macaca, organization of the pulmonary nerve bundles into groups associated with the bronchial system, bronchial arterial system, and pulmonary vein occurs only after a certain depth in the hilar parenchyma.

The peribronchial nerve bundles are situated in the connective tissue around the bronchi and bronchioles. These bundles have a mixed population of myelinated and non-myelinated fibres. The mixed nature of these nerves has been described similarly in other species (Berkley, 1893; Elftman,

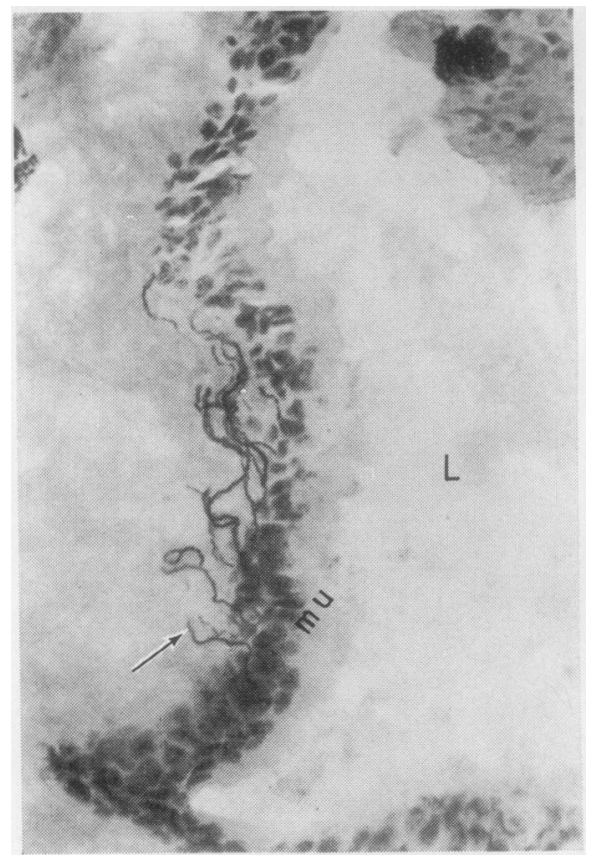

FIG. 6. Nerves reaching the basal layer of mucosal cells and appearing to end on them (arrow). These nerves arise from submucosal nerves ( $L=$ lumen? $m u=m u c o s a)$ (Silver impregnation $\times 126)$.

1943; Fisher, 1965; El-Bermani et al., 1970 El-Bermani, 1973a and b). Both components of the peribronchial bundles are AChE-positive, an we have found none demonstrating fluorescenco for the presence of catecholamines (El-Bermani 1973a and b). Thus these nerves must bo cholinergic. There is a decrease in the ratio of myelinated to non-myelinated nerves as the bundle proceeds deep into the lung parenchyma the most marked reduction occurring in the presence of large numbers of ganglion cells. This finding is in accord with our previous observation in the monkey lung (El-Bermani, 1973a and bo and in the rat lung (El-Bermani et al., 1970). Sinces the ganglion cells innervated by these myelinate fibres also react positively to $\mathrm{AChE}$, it is likely that the fibres represent preganglionic para sympathetic nerves. The ganglion cells af secondary cholinergic neurons of the vagal para sympathetic system to the lung (Larsell, 1922; Nadel, 1974). The preganglionic nerves end of the ganglion cells in a basket-like ending (Figs 2 and 9). The basket-like arrangement of the preganglionic axon terminals were boutons around the soma. 


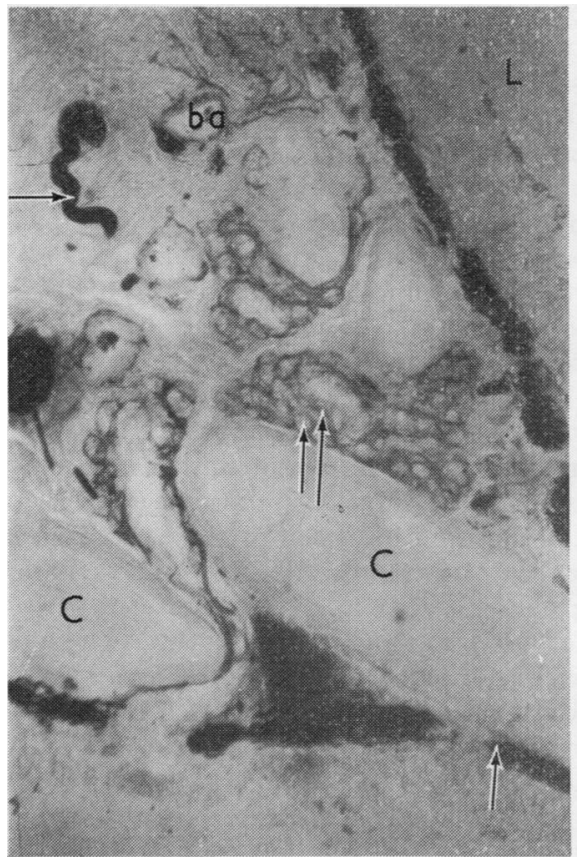

FIG. 7. Acetylcholinesterase-containing nerves in bundles associated with the bronchial system (single arrow) and investing acinar cells of the submucosa (double arrow). The cartilagenous plates of the bronchial wall are labelled C. A bronchial artery (ba) with acetylcholinesterase-positive nerves penetrating its walls contributes nerves to the bronchial wall ( $L=$ lumen; sm=smooth muscle) (Acetylcholinesterase $\times 64)$.

The bronchial nerves are distributed in the adventitio-muscular junction and in submucosal groups. This basic pattern is similar to previous findings in different species (Larsell, 1922; ElBermani et al., 1970; El-Bermani, 1973a and b) but is in contrast to observations that the main contribution to bronchial innervation is from a perivenous source (Takino, 1933). The subchondral nerve plexus contributes AChE-containing innervation to the mucosa of the large bronchi. These fibres form a network of fine nerves around the acinar gland cells. Both the extra and subchondral nerve plexuses are associated with ganglion cells.

The perimuscular nerve plexuses are formed of a network of intermeshed varicose nerves distributed in a three-dimensional pattern throughout the muscle bands. The maximum concentration of these nerves was observed at the bifurcation of the bronchioles. At these points the plexuses

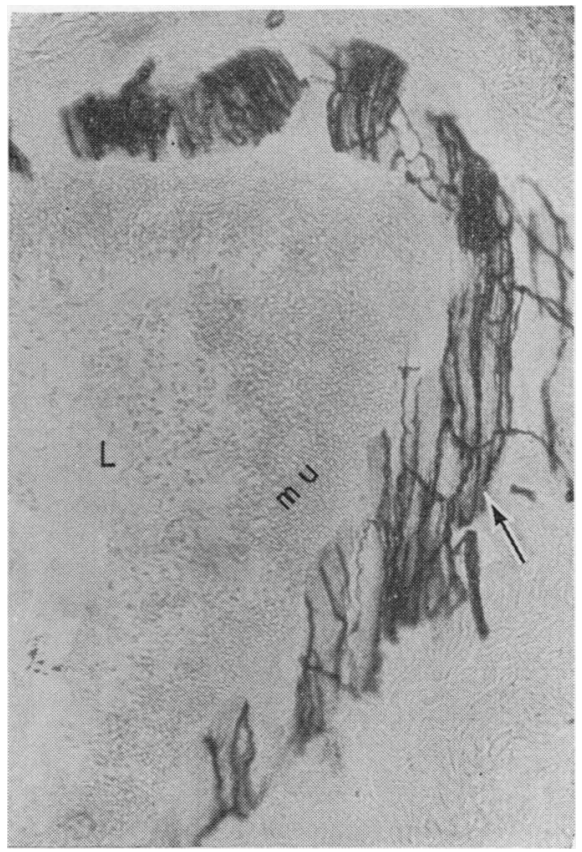

FIG. 8. Acetylcholinesterase-containing nerve plexus (arrow) associated with bronchiolar smooth muscle ( $L=$ lumen; $\quad m u=m u c o s a) \quad$ (Acetylcholinesterase $\times 126)$.

receive additional nerves from nearby ganglion cells. These varicose nerves represent terminal endings to the muscles similar to those of other species (El-Bermani et al., 1970; Spencer and Leof, 1964; Honjin, 1956a and b). The perimuscular varicose terminal plexuses receive their innervation from adventitial nerve bundles and adventitial ganglion cells. The bronchi receive a contribution for nerve fibres around some of the large branches of bronchial artery. All these contributing nerves contain AChE. The origin of these perimuscular nerves and their high content of AChE suggest that they are parasympathetic postganglionic nerves. Vagal stimulation has been shown to produce constriction of the trachea and bronchioles with the maximum effect in the intermediate size bronchioles (Nadel, Cabezas, and Austin, 1971). It seems probable that the nerves observed in the present studies represent those which would mediate this type of bronchial constriction. The AChE-containing innervation of the bronchiolar muscle was traced as far as the terminal bronchioles in the present studies. In physiological studies on dogs, Nadel et al. (1971) showed that vagal stimulation has no effect on the 


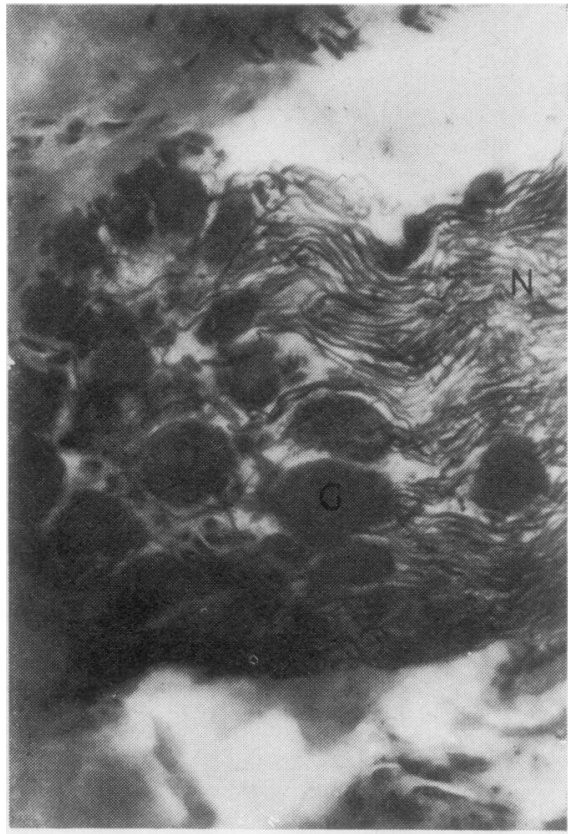

FIG. 9. Acetylcholinesterase-positive reaction of ganglion cells $(G)$ near the hilum. Acetylcholinesterase-positive nerves can be seen to end on these cells $(N=$ nerve bundle) (Acetylcholinesterase $\times 260)$.

terminal bronchioles and alveolar ducts. Thus it appears that there is a major difference in the extent of bronchiolar innervation between the dog and the monkey. Hirsch and Kaiser (1969) described in a morphological study of the dog a continuous innervation of the bronchial system involving the alveolar wall. Our results and the physiological results of Nadel et al. (1971) are in marked contrast to those of Hirsch and Kaiser (1969), whose silver staining appears to have produced artifacts due to staining of connective tissue.

Since we have been unable to demonstrate catecholamine-containing nerves in the bronchial musculature (El-Bermani, 1973a and b) and because of the strong AChE reactions in the innervation of the bronchial musculature as well as in the contributing nerves, we believe that most, if not all, of the innervation to the airway smooth muscle in the monkey is cholinergic. This is in accord with the work of Hebb (1969). The presence of cholinergic innervation has been demonstrated physiologically by experiments which showed that the airways of dogs, cats, rabbits, and humans are tonically constricted by vagal efferent activity (Nadel and Widdicome, 1962; $\underset{\overrightarrow{3}}{\overrightarrow{3}}$ Olson et al., 1965; Karczewski and Widdicome, 1969). In reimplanted lung the airway smooth muscle is unreactive to vagal stimulation, indi- $-\frac{O}{\omega}$ cating that parasympathetic vagal fibres con- $\bar{\oplus}$ tribute to the airway smooth muscle innervation 0 (Edmunds, Graf, and Nadel, 1971). The presence of parasympathetic ganglia, which contribute $\vec{\circ}$ directly to the innervation of the bronchioles and are in close proximity to the bronchioles, is $\vec{\omega}$ reflected in the fast reinnervation of reimplanted $\stackrel{P}{\vec{*}}$ dog lung (Nadel, 1974). The parasympathetic $\vec{x}$ innervation of bronchiolar muscle is important in histamine-initiated bronchoconstriction, which is? abolished by cutting the pulmonary vagi (Dekock $\vec{\sigma}$ et al., 1966) and has been proposed to be a partly

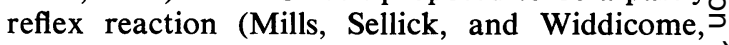
1969; Nadel, 1974).

The submucosal nerves were AChE-positive and were derived from either the adventitial, subchondral plexuses or, in larger bronchi, from $\vec{\theta}$ contributions from the bronchial artery choli- $r$ nergic nerves. The submucosal plexus consists of nonmyelinated fibres present in the connectives tissue and in close relation to the mucosa itself. The presence of such nerves agrees with results demonstrated in other animal species (Larsell, $\stackrel{\odot}{\varrho}$ 1922; Honjin, 1956a and b; Spencer and Leof, $\vec{F}$ 1964), although we have found no intracellular 3 or intra-epithelial endings as described by Hirsch $\supset$ et al. (1968). Our finding is in agreement with thato of Jefferey and Reid (1973) who, in an extensive electron microscopic study found intra-epithelialo nerves in the trachea and extrapulmonary bronchi and none in the intrapulmonary airways. We haveo not differentiated sensory endings in the bronchial 3 . system using histological or histochemicalo methods. No knob-like sensory endings as described by McLelland (1972) in birds have beeno found. Both previously mentioned authors used the silver impregnation method of Bielschowsky을 (1961), which produces a coarse non-specific silver precipitate, a characteristic artifact seen by us. with this method. A few myelinated nerves which 0 showed no AChE reaction were observed in the centre of the submucosal fold. The presence of myelination to the position of these nerves near the mucosal cell layer and the lack of $\mathrm{AChE}_{\Phi}^{\mathrm{C}}$ suggest that these nerves are sensory. Mills et al. $\stackrel{?}{?}$ (1969), based on physiological evidence, have 0 postulated that irritant receptors are present in

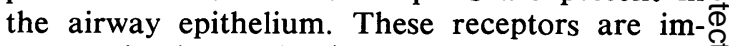
portant in the production of asthma, as aerosols $\vec{D}$ of acetylcholine induce an increase in airway resistance of $250 \%$ which remains for more than 
10 minutes (Gayrard et al., 1971; Svedmyr and Thiringer, 1971). The response has been shown to be a reflex one mediated through the vagus and blocked by atropine (Widdicome, 1974). Application of novocaine to the vagi blocks the bronchoconstriction (Ulmer and Islam, 1974). The sensory fibres as at present described may be those involved in the reflex increase in pulmonary resistance in response to irritants (Lawther et al., 1973).

The cholinergic nerves seen in the submucosa and in direct relation to the mucosal cells probably represent parasympathetic innervation to the glandular cells in this tissue.

This work was supported by grant HE 14524-04 from the National Heart and Lung Institute.

\section{REFERENCES}

Berkley, H. J. (1893). The intrinsic pulmonary nerves by the silver method. The Journal of Comparative Neurology, 3, 107.

Bielschowsky, M. (1961). In: Pathological Technique, edited by F. B. Mallory, p. 158. Hafner Publishing Company, New York.

Dekock, M. A., Nadel, J. A., Zwi, S., Colebatch, H. J. H., and Olsen, C. R. (1966). New method for perfusing bronchial arteries; histamine bronchoconstriction and apnea. Journal of Applied Physiology, 21, 185.

Dogiel, A. S. (1898). Die sensiblen Nervenendigungen im Herzen und in den Blutgefässen der Säugethiere. Archiv für mikroskopische Anatomie und Etwick, 52, 44.

Edmunds, L. H., Graf, P. D., and Nadel, J. A. (1971) Reinnervation of the reimplanted canine lung. Journal of Applied Physiology, 31, 722.

El-Badawi, A. and Schenk, E. A. (1966). Dual innervation of the mammalian urinary bladder. The American Journal of Anatomy, 119, 405.

El-Bermani, Al-W. (1973a). Innervation of the rat lung. Acetylcholinesterase-containing nerves of the bronchial tree. The American Journal of A natomy, 137, 19.

(1973b). Innervation of the Rhesus monkey lung. The Anatomical Record, 175, 313.

, McNary, W. F., and Bradley, D. E. (1970). The distribution of acetylcholinesterase and catecholamine containing nerves in the rat lung. The Anatomical Record, 167, 205.

Elftman, A. G. (1943). The afferent and parasympathetic innervation of the lungs and trachea of the dog. The American Journal of Anatomy, 72, 2.

Fisher, A. W. F. (1965). The intrinsic innervation of the pulmonary vessels. Acta Anatomica, 60, 481.

Fitzgerald, M. J. T. (1964). The double impregnation silver technique for nerve fibers in paraffin sections. Quarterly Journal of Microscopic Sciences, 105, 354.
Gayrard, P., Orehek, J., and Charpin, J. (1971). Comparative study of a new beta-adrenergic stimulant in asthma; salbutamol. Postgraduate Medical Journal, 47, Supplement, 42, p. 46.

von Hayek, H. (1960). The Human Lung, p. 315. Hafner Publishing Company, New York.

Hebb, C. (1969). Motor innervation of the pulmonary blood vessels of mammals. In: The Pulmonary Circulation and Interstitial Tissue, 195th edition, edited by A. P. Fishman and H. H. Hecht. University of Chicago Press, Chicago.

Hillarp, N. A. (1946). Structure of the synapse and the peripheral innervation apparatus of the autonomic nervous system. Acta Anatomica, Supplement 4, 2, p. 1.

Hirsch, E. F. and Kaiser, G. C. (1969). The Innervation of the Lung. Thomas, Springfield, Illinois.

- Barner, H. B., Nigro, S. L., Hamouda, F., Cooper, T., and Adams, W. E. (1968). The innervation of the mammalian lung. III. Regression of the intrinsic nerves and of their afferent receptors following thoracic sympathectomy, cervical vagotomy or thoracic stripping of the vagus. Archives of Surgery, 96, 149.

Honjin, R. (1956a). On the nerve supply of the lung of the mouse, with special reference to the structure of the peripheral vegetative nervous system. Journal of Comparative Neurology, 105, 587.

(1956b). Experimental degeneration of the vagus and its relation to the nerve supply of the lung of the mouse, with special reference to the crossing innervation of the lung by the vagi. Journal of Comparative Neurology, 106, 1.

Jefferey, P. and Reid, Lynne (1973). Intra-epithelial nerves in normal rat airways: a quantitative electron microscopic study. Journal of Anatomy, 114, 35 .

Karczewski, W. and Widdicome, J. G. (1969). The effect of vagotomy, vagal cooling and efferent vagal stimulation on breathing and lung mechanics of rabbits. Journal of Physiology, 201, 259.

Karnovsky, M. J. and Roots, L. (1964). A "directcoloring" thiocholine method for cholinesterases. Journal of Histochemistry and Cytochemistry, 12, 219.

Kuntz, A. (1953). Auntonomic Nervous System, 4th edition. Lea and Febiger, Philadelphia.

Larsell, O. (1921). Nerve terminations in the lung of the rabbit. Journal of Comparative Neurology, 33, 105 .

(1922). The ganglia, plexuses, and nerveterminations of the mammalian lung and pleura pulmonalis. Journal of Comparative Neurology, 35, 97.

Lawther, P. J., Lord, P. W., Brooks, A. G. F., and Waller, R. E. (1973). Air pollution and pulmonary airway resistance: a pilot study. Environmental Research, 6, 424.

McLelland, J. (1972). Afferent nerve endings in the avian lung: observations with the light microscope. Experimentia, 28, 188. 
Mills, J. E., Sellick, H., and Widdicome, J. G. (1969). Activity of lung irritant receptors in pulmonary microembolism, anaphylaxis and drug-induced bronchoconstrictions. Journal of Physiology, 203, 337.

Mitchell, G. A. G. (1956). Cardiovascular Innervation, p. 261. Livingstone, Edinburgh.

Nadel, J. A. (1974). Parasympathetic nervous control of airway smooth muscle. Part II. Agent and airway response. Annals of the New York Academy of Sciences, 221, 99.

- Cabezas, G. A., and Austin, J. H. M. (1971). In vivo roentgenographic examination of parasympathetic innervation of small airways. Investigative Radiology, 6, 9.

and Widdicome, J. G. (1962). Effect of changes in blood gas tensions and carotid sinus pressure on tracheal volume and total lung resistance to air flow. Journal of Physiology, 163, 13.

Namba, T., Nakamura, T., and Grob, D. (1967). Staining for nerve fiber and cholinesterase activity in fresh frozen sections. American Journal of Clinical Pathology, 47, 74.

Olsen, C. R., Colebatch, H. J. H., Mebbel, P. E., Nadel, J. A., and Staub, N. C. (1965). Motor control of pulmonary airways studied by nerve stimulation. Journal of Applied Physiology, 20, 202.
Spencer, H. and Leof, D. (1964). The innervation of the human lung. Journal of Anatomy, 98, 599.

Stirling, W. (1876). Nervous apparatus of the lung British Medical Journal, 2, 401.

Svedmyr, N. and Thiringer, G. (1971). The effects of salbutamol and isoprenaline on beta-receptors in patients with chronic obstructive lung disease Postgraduate Medical Journal, Supplement, 47, p. 44.

Takino, M. (1933). Über die Innervation derLungengefasswand, besonders über das Vorkom $\vec{\omega}$ men der Ganglienzellen an der Gefässwand dep Venae pulmonales and über die Vertbreitungs zustände der Lungenblutgefässnerven bei def Fledermaus. I. Mitteilung. Acta Scholae Medicinalis Universitatis in Kioto, 15, 303.

Ulmer, W. T. and Islam, M. S. (1974). Diछ̈ Azetylcholinempfindlichkeit des Bronchialbaumes? Respiration, 31, 137.

Widdicombe, J. G. (1974). Reflex function of the lung. Bulletin de Physio-Pathologic Respiratoire 10, 65 .

Requests for reprints to: Professor Al-Walid I El Bermani, Department of Anatomy, Boston University School of Medicine, Boston, Massachusetts, USA. 